\title{
Monitoring Genetic Population Biomarkers for Wastewater-Based Epidemiology
}

\author{
Zhugen Yang, ${ }^{\dagger, \S}$ Gaolian Xu, ${ }^{\dagger, \S}$ Julien Reboud, ${ }^{\dagger}$ (i) Barbara Kasprzyk-Hordern, ${ }^{\ddagger}$
} and Jonathan M. Cooper* ${ }^{* \dagger}$

${ }^{\dagger}$ Division of Biomedical Engineering, School of Engineering, University of Glasgow, Oakfield Avenue, Rankine Building, Glasgow, United Kingdom

${ }^{\ddagger}$ Department of Chemistry, University of Bath, Bath BA2 7AY, United Kingdom

\section{Supporting Information}

ABSTRACT: We report a rapid "sample-to-answer" platform that can be used for the quantitative monitoring of genetic biomarkers within communities through the analysis of wastewater. The assay is based on the loop-mediated isothermal amplification (LAMP) of nucleic acid biomarkers and shows for the first time the ability to rapidly quantify human-specific mitochondrial DNA (mtDNA) from raw untreated wastewater samples. mtDNA provides a model population biomarker associated with carcinogenesis including breast, renal and gastric cancers. To enable a sample-to-answer, field-based technology, we integrated a filter to remove solid impurities and perform DNA extraction and enrichment into a low cost lateral flow-based test. We demonstrated mtDNA detection over seven consecutive days, achieving a limit of detection of 40 copies of human genomic DNA per reaction volume. The assay can be performed at the site of sample collection, with minimal user intervention, yielding results within $45 \mathrm{~min}$ and providing a method to monitor public health from wastewater.
$\mathrm{W}$ astewater-based epidemiology has recently been shown to be an innovative and promising tool for the estimation of community-wide drug, ${ }^{1,2}$ alcohol, ${ }^{3}$ and tobacco use, ${ }^{4}$ as well as for the monitoring of oxidative stress biomarkers such as F2-isoprostanes. ${ }^{5}$ Generally, drug residues and their metabolites, or other biomarkers excreted by humans in a given area (e.g., a city) pool within urban wastewater treatments plants, from which samples can be collected and analyzed. When compared with conventional population survey methods, ${ }^{2}$ this approach offers a near real-time and costeffective evaluation of community-wide diseases (such as cancer) or behaviors (such as drug-abuse), with the potential to influence local, regional, and national policy.

This research field holds great promise for the monitoring of noncommunicable diseases (e.g., diabetes, cardiovascular disease) as well as infectious diseases (e.g., sexually transmitted infections) by providing a means to assess the levels of specific disease biomarkers in wastewater. ${ }^{6}$ The technology has the potential to provide an early warning sensing system that could, in future, enable government agencies to deliver effective interventions based on prevalence.

In order to estimate the public health status using these methods, wastewater-based epidemiology requires human and disease-specific biomarkers. The criteria for such candidate biomarkers have been outlined previously. ${ }^{8}$ Briefly, they should be excreted in bodily fluids predictably, as well as being detectable and stable in wastewater. Such biomarker proxies must also be unique to humans, and of low variance in the per capita rate of daily excretion. Accordingly, DNA biomarkers are prime candidates ${ }^{8,9}$ due to their stability, ${ }^{10}$ and as such, environmental biomarkers potentially outperform metabolites as they are more persistent (e.g., ecgonine methylester, a metabolite of cocaine, shows $20 \%$ degradation after $12 \mathrm{~h}$ storage). ${ }^{11}$

DNA is constantly excreted by humans and can be quantified specifically, using particular DNA sequences as the biomarker. The change of DNA sequence and structure via processes, such as damage, repair, and mutation, might also provide more subtle indications of the evolution of disease at population level. ${ }^{8,12}$

In general, the extent of the knowledge gained will be subject to the number of individuals carrying the disease and the sensitivity of the analytical approaches used to identify and quantify the biomarkers. These characteristics combine to make it a population biomarker of choice. ${ }^{8,12}$

The mitochondrial genome is $\sim 16.5 \mathrm{~kb}$ in size and is present in multiple copies in individual mitochondria. It is used as a biomarker in a number of cancers including breast, renal and gastric cancers. ${ }^{13}$ We recently proposed the use of community sewage sensors as rapid and inexpensive alternatives to classical analytical methods for the detection of sewage biomarkers. ${ }^{7}$ We have previously also demonstrated that community sewage

Received: June 12, 2017

Accepted: August 17, 2017

Published: August 17, 2017 
Scheme 1. Illustration of the Extraction and Detection of Genomic Population Biomarkers in the Field with LAMP- Lateral Flow Device

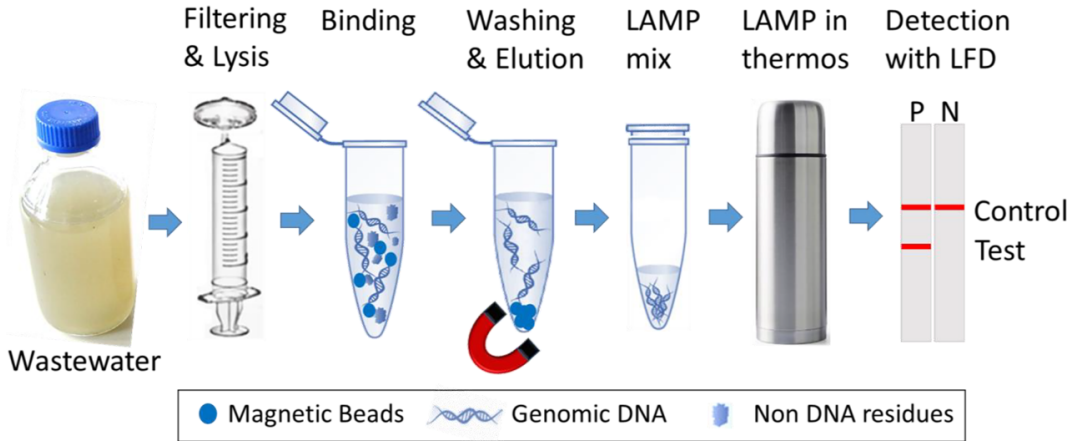

sensors are able to detect a wide range of markers (e.g., prostate specific antigen ${ }^{14}$ and illicit drugs such as cocaine $\left.{ }^{15}\right)$. In a proofof-concept study, we showed that human-specific mtDNA could be detected in sewage with an electrochemical DNA sensor by using a ferrocenyl DNA intercalator as a redox marker. ${ }^{9}$ However, the limitations of affinity-based probe sensors coupled with the complexity of the sewage matrix require the development of an amplification strategy to improve the assay sensitivity to achieve the on-site monitoring.

Recently, loop-mediated isothermal amplification (LAMP) has emerged as a promising technique for the amplification of a wide spectrum of targets. ${ }^{16}$ Compared to gold-standard techniques such as polymerase chain reaction (PCR), which require precise temperature control during thermocycling, LAMP provides a simple, rapid, specific, and cost-effective amplification method. ${ }^{17}$ Additionally, LAMP has been coupled with microfluidic sample preparation, ${ }^{18}$ capillary platforms, ${ }^{19,20}$ and paper devices, ${ }^{21}$ demonstrating its capabilities within a point-of-care test.

In this paper, we now demonstrate a portable LAMP assay to detect human-specific mtDNA in wastewater, as a population biomarker, with the potential to monitor public health. We demonstrate that the extraction of DNA from wastewater using a commercial magnetic bead methodology, ${ }^{22}$ can be performed in the field, without using central laboratory facilities.

The assay was performed in a portable vacuum flask filled with hot water (e.g., a thermos), providing the required temperature for the reaction $\left(60^{\circ} \mathrm{C}-64^{\circ} \mathrm{C}\right)$ for over $45 \mathrm{~min} .{ }^{19}$ At the end of the reaction, the amplicon produced was transferred to a lateral flow device to be read visually (Scheme 1 ). The working principle of the commercial lateral flow device, as previously published, ${ }^{23}$ is illustrated in Figure S1 and detailed in the Materials and Methods. The entire assay, from the sample to the answer, is completed within $\sim 45 \mathrm{~min}$.

\section{MATERIALS AND METHODS}

Reagents. The Nalgene $25 \mathrm{~mm}$ syringe filters (nylon membrane - pore size of $0.45 \mu \mathrm{m}$ ) were purchased from Thermo Scientific. Gsp SSD DNA polymerase (large fragment), $\mathrm{MgSO}_{4}$, and betaine were from OptiGene Ltd. (U.K.). EvaGreen was from Biotium (U.K.). All the primers were synthesized by Eurofins (U.K.; Table S2). SYBR Gold Nucleic Acid Gel Stain was from Life Technologies (U.K.). The lateral flow device for LAMP amplification product detection were provided by Ustar Biotech Co., Ltd. (Hangzhou, China). The MagaZorb DNA Mini-Prep kit, mineral oil (CAS Number
8042-47-5), deoxy-ribonucleoside triphosphates (dNTPs), and other reagents were from Sigma-Aldrich (U.K.).

Wastewater Samples. Daily raw wastewater samples were collected from a local wastewater treatment plant in SouthWest England in a week-long sampling campaign. Samples were tested and also frozen for retrospective analysis. The wastewater sample was filtered using a $60-\mathrm{ml}$ syringe $(0.45 \mu \mathrm{m}$ poresized membrane) and lysed chemically before magnetic extraction and LAMP.

LAMP Assay. The specific primer set for the LAMP reaction was designed to amplify the human mitochondrial DNA (mtDNA) sequence (Table S1), gene AY972053. Primers were tested for hybrids and hairpin structures using the Integrated DNA Technologies design tools (http://eu.idtdna. $\mathrm{com} /$ pages/scitools). The optimization of detection parameters and the sensitivity of the LAMP assay were performed on a real time PCR machine (ABI 7500 Fast real-time PCR, Thermo Fisher Scientific, U.K.) at $63{ }^{\circ} \mathrm{C}$. The LAMP amplicon was analyzed on a $1 \%(\mathrm{w} / \mathrm{v})$ agarose gel in TAE $1 \times$ buffer $(\mathrm{pH} 8)$ and the image was recorded by a Bio-Rad reader.

For the lateral flow device based LAMP amplicon detection, the loop primers (MT LPF and MT PLB) were labeled at their $5^{\prime}$ ends with biotin and fluorescein isothiocyanate (FITC), respectively, as reported in. ${ }^{23}$ The amplicon of LAMP was transferred with a pipet to the sample pad of the lateral flow device, for detection. A positive test was indicated by the presence of two red lines, one assigned to the target sample and another corresponding to the control, which confirms if the test is valid. A negative test was indicated with a single red line. If there was no red line from the control, the test was regarded as invalid.

After optimization, we used the following composition for the LAMP mix: a $20 \mu \mathrm{L}$ real-time LAMP mix solution was composed of $0.8 \mu \mathrm{M}$ inner primers (FIP and BIP), $0.6 \mu \mathrm{M}$ of the loop primers (LFR and LRP), $0.1 \mu \mathrm{M}$ of bumper primers (F3 and B3), $1.25 \mu \mathrm{M}$ EvaGreen, 0.4 Unit of Gsp SSD DNA polymerase, $0.4 \mathrm{mM}$ of each dNTPs, $4.0 \mathrm{mM}$ of $\mathrm{MgSO}_{4}, 50$ $\mathrm{mM}$ Tris- $\mathrm{HCl}$ (pH 8.1), $30 \mathrm{mM} \mathrm{KCl}, 30 \mathrm{mM}\left(\mathrm{NH}_{4}\right)_{2} \mathrm{SO}_{4}, 0.1 \%$ Triton X-100, and $1 \mathrm{M}$ of betaine. A total of $20 \mu \mathrm{L}$ of mineral oil was introduced to cover the LAMP solution to prevent the evaporation during the incubation.

Extraction and Characterization of DNA. The whole process contained four steps: cell concentration, DNA extraction with MagaZorb reagents, DNA isothermal amplification in a vacuum flask filled with hot water (using a thermometer to check temperature when required), and lateral follow devices for amplicon detection. The human genomic 
DNA from the cultured cell was isolated according to the manufacturer's manual (DNeasy Kit (Qiagen)), and then quantified with a NanoDrop 2000 Spectrophotometer (Thermo Fisher Scientific, U.S.).

The extraction and test process were as follows: $40 \mathrm{~mL}$ water sample was passed through a filter $(0.45 \mu \mathrm{m}$ pore size $)$ using a syringe. Cells and other coarse material was concentrated by the filter. After the addition of $400 \mu \mathrm{L}$ of lysis buffer in the syringe, the filtered water sample was incubated at room temperature for $10 \mathrm{~min}$ for DNA release. The released DNA $(400 \mu \mathrm{L})$ was eluted into a PCR tube with the syringe and mixed with MagaZorb reagent for DNA purification. Finally, 1 $\mu \mathrm{L}$ of eluted DNA (after concentration with magnetic beads) was amplified in a LAMP reaction. The LAMP reaction was incubated within the thermos with a starting temperature of 64 ${ }^{\circ} \mathrm{C}$, for $45 \mathrm{~min}$, and the amplicon was detected with the lateral flow device visually.

Lateral Flow Assay. After amplification, $10 \mu \mathrm{L}$ of amplicons were pipetted onto the lateral flow device, followed by $100 \mu \mathrm{L}$ of testing buffer (saline sodium citrate (SSC) $2 \times$, Sigma, U.K.). The results can be read visually as shown in Figure 1. The whole testing process takes less than 2 min. Figure S1 also illustrates the working principle of the lateral flow device for the specific detection of mtDNA amplicons.

Briefly, if the target was present in the sample and as the specific LAMP reaction took place, amplicons were generated with both biotin and FITC-labeled primers, as a complex bearing two ligands. When this complex was flowed through the lateral flow device containing anti-FITC antibodies and immobilized streptavidin (coated with colored nanoparticles) in the test and control lines, respectively, the two ligands were specifically captured (Figure S1A). This generated two red lines as a positive result. However, if there was no specific amplification, only a biotin-streptavidin conjugation took place on the control line, showing one red line as a negative result (Figure S1B).

\section{RESULTS AND DISCUSSION}

To achieve an accurate and sensitive assay, we optimized the concentration of primers using real-time LAMP (details in the SI). The vacuum flask maintained the reaction temperature in a range between 64.5 and $60.0{ }^{\circ} \mathrm{C}$ over $45 \mathrm{~min}$ (Figure S2), which enabled the LAMP reaction to run successfully (Figure 1).

Serially diluted human genomic DNA with concentrations from 12 to $0.12 \mathrm{ng} \mu \mathrm{L}^{-1}$ in Tris buffer (0.1 M, pH 8.0) were processed through the system, to evaluate the analytical performance (sensitivity and accuracy). Two groups of reactions were performed; one group (lanes 1-4) incubated at $63{ }^{\circ} \mathrm{C}$ using a real time PCR thermocycler (ABI 7500 Fast System, Thermo), enabling precise temperature control; the others (lanes 5-8) were incubated in a thermos that contains about $50 \mathrm{~mL}$ of hot water at $64{ }^{\circ} \mathrm{C}$. After incubation, the amplification products were detected by the lateral flow device, following the manufacturers' instructions. ${ }^{23}$ A positive test was indicated by the presence of two red lines: one assigned to the target sample and another corresponding to the control that confirms that the test is valid. Results (Figure 1A) show no difference between the two heating methodology. The amplicons from the lowest target concentration (0.12 ng $\mu \mathrm{L}^{-1}$ ) were also evaluated with an agarose electrophoresis gel (Figure 1B), which confirmed the similarity of the amplification
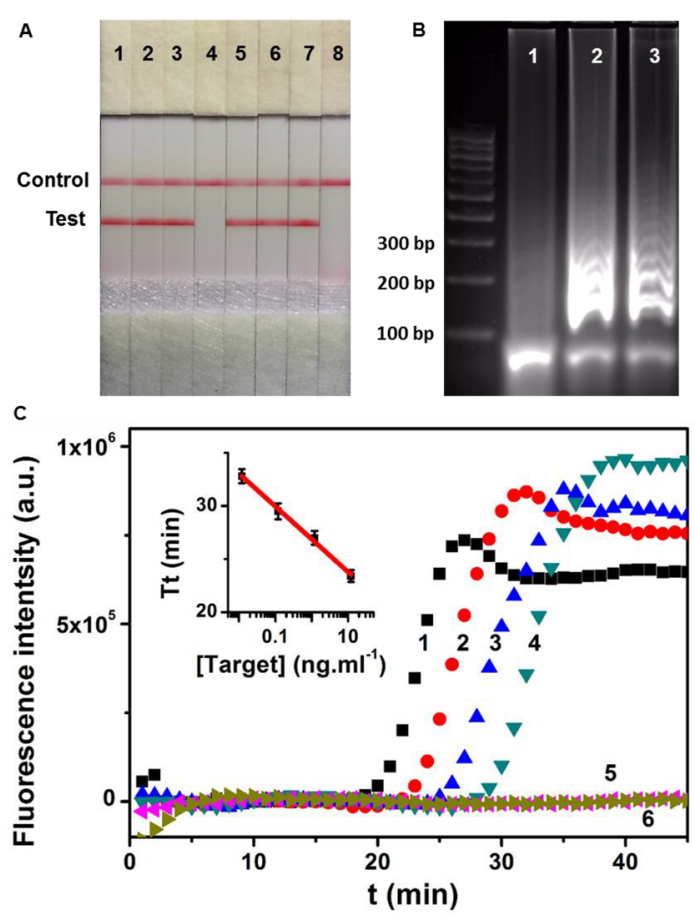

Figure 1. Evaluation of feasibility and analytical performance of the lateral flow device for LAMP assay: (A) Image of the lateral flow device for the detection of LAMP reactions with serially diluted target concentrations using the thermos and different incubation conditions. 1-4 were incubated at $63{ }^{\circ} \mathrm{C}$, while 5-8 were incubated in the thermos; $1 / 5,12 \mathrm{ng} \mu \mathrm{L}^{-1}$; 2/6, $1.2 \mathrm{ng} \mu \mathrm{L}^{-1}$; 3/7, $0.12 \mathrm{ng} \mu \mathrm{L}^{-1}$; 4/8, negative. (B) Agarose gel image of the LAMP amplicons: Lane 1, negative control (DNA-free water); Lane $2,0.12 \mathrm{ng} \mu \mathrm{L}^{-1}$ target processed in the $\mathrm{ABI}$ thermocycler; Lane 3, $0.12 \mathrm{ng} \mu \mathrm{L}^{-1}$ target processed in the vacuum flask (see Materials and Methods and SI for details). (C). Real-time LAMP assay for $10 \times$ dilution series of target concentrations; $1,12 \mathrm{ng} \mu \mathrm{L}^{-1}$; $2,1.2 \mathrm{ng} \mu \mathrm{L}^{-1}$; 3, $0.12 \mathrm{ng} \mu \mathrm{L}^{-1}$; 4, 0.012 ng $\mu \mathrm{L}^{-1} ; 5,0.0012 \mathrm{ng} \mu \mathrm{L}^{-1}$; 6 , negative control (no target DNA). The inset is threshold time, $T_{t}$ (defined as the time corresponding to $50 \%$ of the maximum fluorescence intensity) as a function of target concentration. ${ }^{19}$ Data is the average from three independent measurements. Error bars are the standard deviation around the mean $(n=3)$. The data was fitted with linear regression (Figure 3C, inset; $\left.R^{2}=0.99\right)$.

and thus the compatibility of thermos-based technique for LAMP amplification. ${ }^{19}$

Figure 1C shows the results of the real-time LAMP amplification (using the fluorescent dye EvaGreen as a reporter). As the concentration of target DNA increased, the exponential increase in the fluorescence intensity started earlier. The sensitivity reached 40 copies of human genomic DNA per reaction, up to 10 -fold better than reported real-time PCR techniques on similar environmental samples. ${ }^{24}$ The LAMP assay permits linear interrogation of mtDNA level in the range from $0.012 \mathrm{ng} \mu \mathrm{L}^{-1}$ to $12 \mathrm{ng} \mu \mathrm{L}^{-1}$ (40 to 40000 copies of human genomic DNA per reaction, Figure 1C, inset), thus, providing a route for quantification of the initial target DNA.

To evaluate the performance of the assay for wastewater samples, we first detected mtDNA in tap water spiked with cultured human cells MG63 (osteosarcoma, as a model of a cancer cell containing human-specific mtDNA, gene AY972053) with an initial concentration of $2.5 \times 10^{6}$ cells $\mathrm{ml}^{-1}$. The cells were spiked into $40 \mathrm{~mL}$ tap water and serially diluted to evaluate the dose response for the detection of 

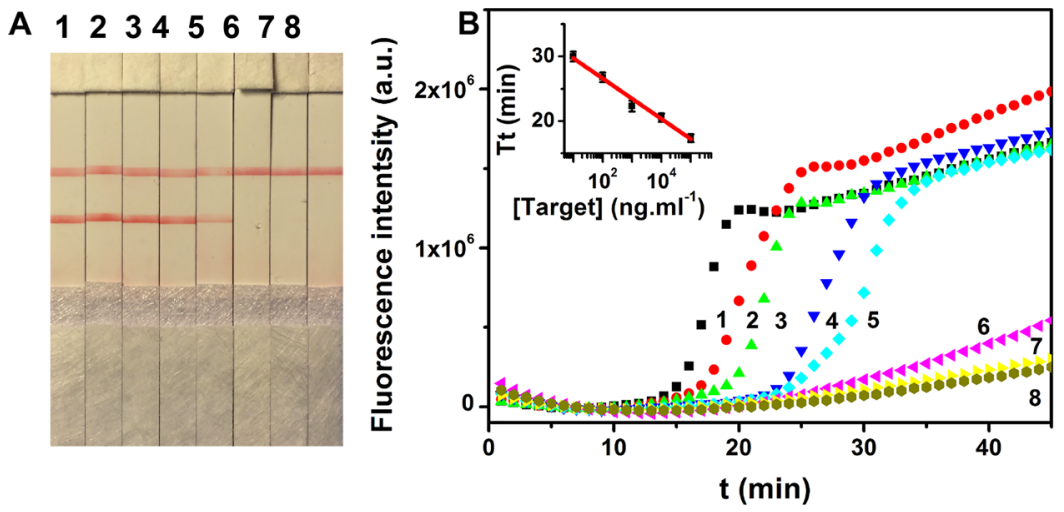

Figure 2. Lateral flow device for the detection of mtDNA in tap water spiked with cultured cells. The mtDNA was detected with the lateral flow device from tap water spiked with different concentrations of cultured human cells: (A) Image of the lateral flow device used for the detection of 10fold serial dilutions of cultured human cells spiked in tap water $(1-6): 1,10^{5}$ cells $\mathrm{mL}^{-1} ; 2,10^{4}$ cells $\mathrm{mL}^{-1} ; 3,10^{3}$ cells $\mathrm{mL}^{-1} ; 4,10^{2}$ cells $\mathrm{mL}^{-1} ; 5,10$ cells $\mathrm{mL}^{-1}$; 6, 1 cell mL ${ }^{-1}$; 7, tap water; $8, \mathrm{ddH}_{2} \mathrm{O}$ as a negative control. (B) Analytical sensitivity of real-time LAMP (samples 1 to 8 as in A). The higher background signal observed (samples 6-8), compared with samples 5-6 in Figure 1C, is likely due to the accumulation of signal from the nonspecific interaction between dyes and DNA molecules, potentially promoted by the impurities of the spiked cultured cells. The inset presents a linear fit for measurements of threshold time $T_{\mathrm{t}}$ for samples $1-5\left(R^{2}=0.99\right)$.
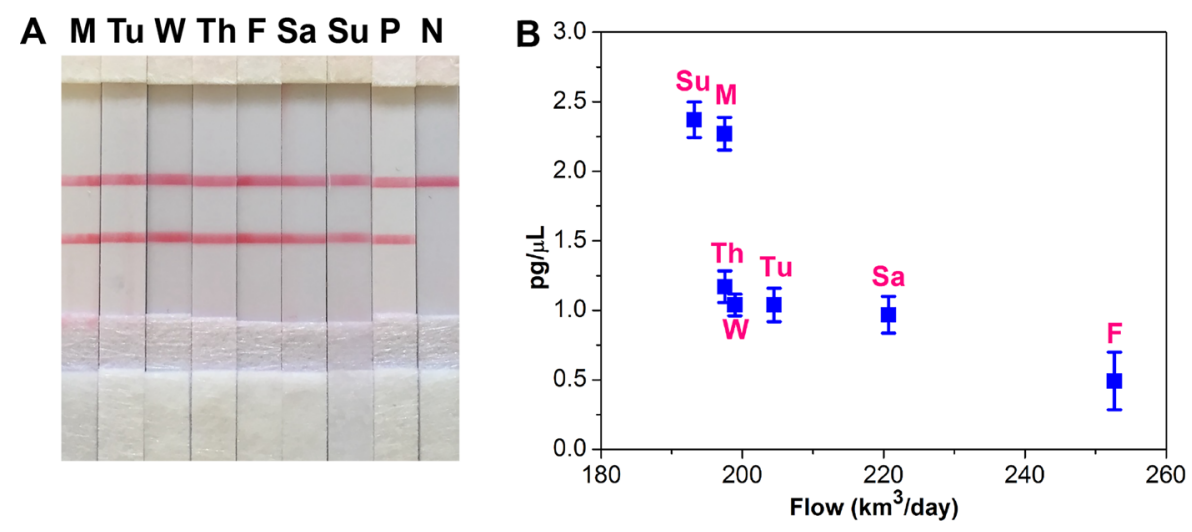

Figure 3. Lateral flow device for the detection of mtDNA in raw wastewater: (A) image of the lateral flow device results from the detection of mtDNA in wastewater from 7 consecutive days, incubated in a thermos as described; (B) concentration of mtDNA in wastewater using real-time LAMP to quantify it, as a function of the flow rate of wastewater treatment plant.

mtDNA with lateral flow devices (Figure 2A), after extraction (using a syringe; details in SI) and amplification. Results show that we were able to detect as low as 10 cells $\mathrm{mL}^{-1}$, comparable to the results from the real-time assay (Figure $2 \mathrm{~B}$ ).

We validated this new platform for application in the field, using wastewater samples collected consecutively over 7 days from a treatment plant in South-West England (Figure 3A). The assays were also run on the real-time platform to quantify the amount of DNA. The mean threshold time of the real-time LAMP $(p<0.05)$ with the concentration of mtDNA in sewage decreased with increasing the flow rate of sewage but the total amount of human-specific mtDNA in sewage did not vary throughout the week. This can be understood from the fact that the content of mtDNA shed by the local population is expected to be correlated to the size of the population, which may not be expected to vary significantly over short periods of time (although it is acknowledged at weekends and in holidays, urban populations can vary). The content of mtDNA shed by the local population will be inversely dependent on rainfall (which increases total volume of runoff above the levels of wastewater generated by the population).

The results of the lateral flow device analysis (read visually to allow for field testing, at the wastewater treatment plant) are in close agreement with those from real-time LAMP. In addition, we show that this technique can quantify the mtDNA in wastewater, Figure $1 \mathrm{C}$, a capability that could enable baselines to be established for certain diseases (providing a method for the recording of changes in public health status and the epidemiology of diseases and their control). Such testing could be performed in the field with a portable machine for isothermal assay (e.g., Optigene, U.K.). One potential limitation is that the test is reliant on the availability of a source of hot water (for the LAMP cycling). Examples of how this constraint could be overcome involve using a range of different technologies, depending on the location where the assay is to be performed, and may range from using a batteryoperated heater $^{25}$ to exothermic chemical reactions ${ }^{26}$ and solar ovens. $^{27}$

One long-term aim is to develop a sensitive and portable device for on-site monitoring of public health biomarkers. The LAMP assay can overcome the challenges involved in rapidly detecting low levels of human genome in wastewater, that conventional affinity-based biosensors have been shown to have difficulties in delivering. In addition, as a sample-to-answer portable technology, the technique can be implemented on-site and does not involve sample transportation and storage (which can potentially result in sample contamination and degradation). 


\section{CONCLUSION}

In summary, we have developed a cost-effective and easy-to-use isothermal sensing device for the identification of population biomarkers with the potential for monitoring public health. We designed and demonstrated a LAMP assay for the detection of human specific mtDNA in wastewater, a potential population biomarker associated with cancer. The LAMP assay is able to detect as low as 40 copies of mtDNA from human genomic DNA, with a dynamic range from 40 copies to 40000 copies per reaction. The sensing platform uses a lateral flow device for direct visual readout, allowing for the monitoring of population biomarkers in resource-constrained areas, as a point-of-care test. In addition, this device can be used with minimal user intervention, as a generic platform for a range of nucleic acids.

In the future we will combine the data with the dynamics of population and rainfall parameters utilized in wastewater-based epidemiology (e.g., fluctuations in population size, other public health biomarkers, and runoff water) to achieve a comprehensive study in which the rapid sensing platform will facilitate monitoring with a strong potential to achieve a real-time study. Crucially, this device may enable the development of early warning sensing systems for public health agencies to initiate effective early interventions in disease control, as well as the collection of quantitative epidemiological evidence to study disease control (including, e.g., social interventions).

\section{ASSOCIATED CONTENT}

\section{S Supporting Information}

The Supporting Information is available free of charge on the ACS Publications website at DOI: 10.1021/acs.analchem.7b02257.

The data for this manuscript is available free of charge from DOI: http://dx.doi.org/10.5525/GLA. RESEARCHDATA.448. Figures S1 and S2 and Table S1 (PDF).

\section{AUTHOR INFORMATION}

\section{Corresponding Author}

*E-mail: jon.cooper@glasgow.ac.uk.

ORCID

Julien Reboud: 0000-0002-6879-8405

Barbara Kasprzyk-Hordern: 0000-0002-6809-2875

\section{Author Contributions}

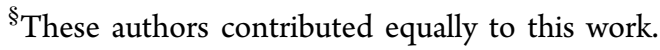

\section{Notes}

The authors declare no competing financial interest.

\section{ACKNOWLEDGMENTS}

The work was supported by EPSRC (EP/K027611/1), ERC 340117, and BBSRC Bb/L00464x/1. G.X. was supported through a College of Science and Engineering Scholarship from the University of Glasgow. J.R. acknowledges a University of Glasgow Fellowship. Z.Y. and B.K.-H. acknowledge EU SEWPROF (317205). Wessex Water is acknowledged for the provision of wastewater samples, which were collected with the help of Dr. E. Castrignanò and Dr. B. Petrie.

\section{REFERENCES}

(1) Ort, C.; van Nuijs, A. L. N.; Berset, J.-D.; Bijlsma, L.; Castiglioni, S.; Covaci, A.; de Voogt, P.; Emke, E.; Fatta-Kassinos, D.; Griffiths, P.; et al. Addiction 2014, 109 (8), 1338-1352.
(2) Thomas, K. V.; Bijlsma, L.; Castiglioni, S.; Covaci, A.; Emke, E.; Grabic, R.; Hernández, F.; Karolak, S.; Kasprzyk-Hordern, B.; Lindberg, R. H.; et al. Sci. Total Environ. 2012, 432, 432-439.

(3) Reid, M. J.; Langford, K. H.; Mørland, J.; Thomas, K. V. Alcohol.: Clin. Exp. Res. 2011, 35 (9), 1593-1599.

(4) Castiglioni, S.; Senta, I.; Borsotti, A.; Davoli, E.; Zuccato, E. Tob. Control 2015, 24 (1), 38-42.

(5) Ryu, Y.; Gracia-Lor, E.; Bade, R.; Baz-Lomba, J. A.; Bramness, J. G.; Castiglioni, S.; Castrignanò, E.; Causanilles, A.; Covaci, A.; Voogt, P. de; et al. Sci. Rep. 2016, 6, 39055.

(6) Thomas, K. V.; Reid, M. J. Environ. Sci. Technol. 2011, 45 (18), $7611-7612$.

(7) Yang, Z.; Kasprzyk-Hordern, B.; Frost, C. G.; Estrela, P.; Thomas, K. V. Environ. Sci. Technol. 2015, 49 (10), 5845-5846.

(8) Gracia-Lor, E.; Castiglioni, S.; Bade, R.; Been, F.; Castrignanò, E.; Covaci, A.; González-Mariño, I.; Hapeshi, E.; Kasprzyk-Hordern, B.; Kinyua, J.; et al. Environ. Int. 2017, 99, 131-150.

(9) Yang, Z.; d'Auriac, M. A.; Goggins, S.; Kasprzyk-Hordern, B.; Thomas, K. V.; Frost, C. G.; Estrela, P. Environ. Sci. Technol. 2015, 49 (9), 5609-5617.

(10) Dejean, T.; Valentini, A.; Duparc, A.; Pellier-Cuit, S.; Pompanon, F.; Taberlet, P.; Miaud, C. PLoS One 2011, 6 (8), e23398.

(11) van Nuijs, A. L. N.; Abdellati, K.; Bervoets, L.; Blust, R.; Jorens, P. G.; Neels, H.; Covaci, A. J. Hazard. Mater. 2012, 239-240, 19-23.

(12) Chen, C.; Kostakis, C.; Gerber, J. P.; Tscharke, B. J.; Irvine, R. J.; White, J. M. Sci. Total Environ. 2014, 487, 621-628.

(13) Xia, P.; An, H.-X.; Dang, C.-X.; Radpour, R; Kohler, C.; Fokas, E.; Engenhart-Cabillic, R.; Holzgreve, W.; Zhong, X. Y. BMC Cancer 2009, 9, 454.

(14) Yang, Z.; Kasprzyk-Hordern, B.; Goggins, S.; Frost, C. G.; Estrela, P. Analyst 2015, 140 (8), 2628-2633.

(15) Yang, Z.; Castrignanò, E.; Estrela, P.; Frost, C. G.; KasprzykHordern, B. Sci. Rep. 2016, 6, 21024.

(16) Zhao, Y.; Chen, F.; Li, Q.; Wang, L.; Fan, C. Chem. Rev. 2015, 115 (22), 12491-12545.

(17) Tomita, N.; Mori, Y.; Kanda, H.; Notomi, T. Nat. Protoc. 2008, 3 (5), 877-882.

(18) Rane, T. D.; Chen, L.; Zec, H. C.; Wang, T.-H. Lab Chip 2015, 15 (3), 776-782.

(19) Xu, G.; Zhao, H.; Cooper, J. M.; Reboud, J. Chem. Commun. 2016, 52 (82), 12187-12190.

(20) Zhang, Y.; Zhang, L.; Sun, J.; Liu, Y.; Ma, X.; Cui, S.; Ma, L.; Xi, J. J.; Jiang, X. Anal. Chem. 2014, 86 (14), 7057-7062.

(21) Xu, G.; Nolder, D.; Reboud, J.; Oguike, M. C.; van Schalkwyk, D. A.; Sutherland, C. J.; Cooper, J. M. Angew. Chem., Int. Ed. 2016, 55 (49), 15250-15253.

(22) Haukanes, B.-I.; Kvam, C. Nat. Biotechnol. 1993, 11 (1), 60-63.

(23) Xu, G.; You, Q.; Pickerill, S.; Zhong, H.; Wang, H.; Shi, J.; Luo, Y.; You, P.; Kong, H.; Lu, F.; et al. J. Med. Virol. 2010, 82 (7), 11431149.

(24) Caldwell, J. M.; Raley, M. E.; Levine, J. F. Environ. Sci. Technol. 2007, 41 (9), 3277-3283.

(25) Herold, K. E.; Sergeev, N.; Matviyenko, A.; Rasooly, A. Rapid DNA Amplification Using a Battery-Powered Thin-Film Resistive Thermocycler. Biosensors and Biodetection; Methods in Molecular Biology; Humana Press, 2009; pp 441-458.

(26) Curtis, K. A.; Rudolph, D. L.; Nejad, I.; Singleton, J.; Beddoe, A.; Weigl, B.; LaBarre, P.; Owen, S. M. PLoS One 2012, 7 (2), e31432.

(27) Dobrowsky, P. H.; Carstens, M.; De Villiers, J.; Cloete, T. E.; Khan, W. Sci. Total Environ. 2015, 536, 206-214. 